
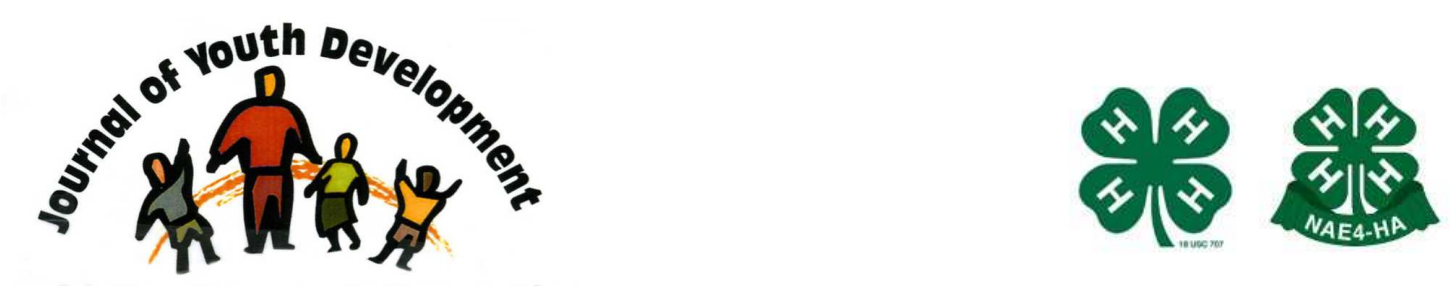

Bridging Research \& Practice

\title{
Engaging Street Youth in an Evaluation of a Community-Based Arts Program
}

\author{
Robin Wright \\ School of Social Work \\ University of Windsor \\ Windsor, Ontario, Canada \\ rwright@uwindsor.ca \\ Lindsay John \\ John Associates \\ Montreal, Quebec \\ Julia Sheel \\ McGill University \\ David Spinner \\ McGill University
}




\title{
JOURNAL OF YOUTH DEVELOPMENT \\ bridging research and practice

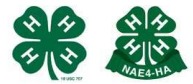

Volume 3, Number 1, Summer 2008

Article 080301FA003

\section{Engaging Street Youth in an Evaluation of a Community-Based Arts Program}

\author{
Robin Wright, \\ University of Windsor \\ Lindsay John, \\ John Associates \\ Julia Sheel and David Spinner \\ McGill University
}

\begin{abstract}
Data from the Edmonton Arts \& Youth Feasibility Study (EAYFS) was used to ascertain the feasibility of engaging street youth in a structured community-based arts program and an outcome-based evaluation. The study engaged 23 street youth in a ten-week multimedia arts program focused on developing prosocial communication, team-building, and problem-solving skills. Results have shown that street youth are highly interested in artistic endeavors; will participate to the best of their circumstances; and will provide reliable data. The youth and staff reported improved art skills, problem-solving capacity, and prosocial communication as well as a decrease in drug use, depression, loneliness, and a greater sense of enjoyment about life. Strengths of the program included the arts media, the non-judgmental environment, and the support from staff. The study suggests that community-based arts programs for street youth could be subjected to a rigorous outcome-based evaluation.
\end{abstract}

\section{Introduction}

Findings from the National Longitudinal Survey of Children and Youth (NLSCY 2002), an ongoing Canadian longitudinal household survey designed to monitor the development and well-being Canadian children, have shed light on the concept of 'youth at risk.' In analyzing the data from the NLSCY, Willms (2002) emphasized youth outcomes rather than risk factors. The approach underscores the fact that there is not a one-to-one relationship between risk factors and vulnerability. Werner and Smith (1982) have shown that some children and youth growing 
up in high-risk environments go on to lead successful lives as adults, whereas others are devastated by such life circumstances.

Nonetheless, if we look at outcomes rather than risk, the most vulnerable youth are probably youth living on the streets. In Maslow's (1954) model of human motivation, a higher need, namely, self-actualization, is expressed only after lower needs are fulfilled. Street youth are faced with the daily struggle of meeting basic survival needs. The marginal nature of living day to day in such a threatening environment, inexorably leads to hopelessness and despair. To further complicate matters, that proportion of society's most vulnerable youth do not have either physical or psychological accessibility to available psychological services. The heavy burden of suffering attributed to these youth is often associated with reduced life quality and limited opportunities to attain socially desirable outcomes (Offord, Lipman, \& Duku, 1998).

Street youth have to cope with a multitude of life stressors such as hunger, homelessness, drug addiction, being in conflict with the law, and involvement in the sex trade. Street victimization also amplifies already high levels of depression and conduct disorders (Whitback, Hoyt, \& Bao, 2000). Research has primarily focused on street youth pathology with little attention paid to intervention and prevention efforts (Kidd, 2003). Few interventions with this population have been formally evaluated. Careful program evaluation of services is sorely needed, especially based on rigorous experimental designs (Robertson \& Toro, 1999).

An innovative approach that has worked with other youth at risk for psychosocial problems is community-based art programs. There is growing research evidence that well-designed and structured community-based arts programs can promote positive youth development and enrich the lives of youths (Eccles \& Templeton-Gootman, 2002; Posner \& Vandell, 1999; Wright, John, Offord, Duku, Rowe, \& Ellenbogen, 2006), improve school performance (Catterall, Chapleau, \& Iwanaga,1999), as well as reduce negative behaviors like delinquency, alcohol and drug abuse (Mahoney, Larson, \& Eccles, 2005). The high costs of the current justice system must be considered in the context of its limited successes. There is evidence that deterrence approaches, such as boot camps, zero tolerance programs, and other punitive exclusionary policies, may actually increase crime and marginalization (Jackson, 2002; Kempinem \& Kurlychek, 2003)

However, little is known about the effects of community-based arts programs on street youth. It seems worthwhile to query whether the methods and procedures that arguably work with youth from at-risk communities will also be effective with a much higher risk group of youth, namely, street youth. Before embarking on an outcome-based study of community-based arts programs as a strategy to improve the psychosocial functioning of street youth, it was deemed necessary to assess the feasibility of such a cost-intensive strategy with that population. Many assume that it would be very difficult to engage street youth in community intervention research given their transient nature, high incidences of drug use, emotional and behavioral problems as well as their general mistrust of adults. Of particular interest for this study are certain practical questions. For example - could street youth, many of them homeless, be engaged in artistic endeavors? Would they demonstrate regular and sustained attendance? Would they be willing to complete self-report questionnaires in a reliable manner?

\section{Existing Literature}

Many researchers have shown a growing interest in arts education programs within schools, youth organizations and in juvenile offender institutions (Darby \& Catterall, 1994; Eisner, 1998; 
Ezell \& Levy, 2003; Offord, Lipman, \& Duku, 1998; Weitz, 1996). A review of the literature reveals that in addition to acquiring art skills, there is evidence of cognitive, academic and psychosocial benefits related to arts education. Experimental studies on the effects of art programs, specifically for high-risk youth in voluntary settings is non-existent. However, there have been a few studies conducted with at-risk youth, with art as a strategy for delinquency prevention.

For example, the YouthARTS Development Project (Clawson \& Coolbaugh, 2001) was designed to identify implement, and refine effective arts-based delinquency prevention programs. Programs were run in three sites in the United States: Atlanta, GA, Portland, OR, and San Antonio, TX. Each of the three sites ran slightly different programs with the common goal of gaining a better understanding of the positive effects of arts-based programming on at-risk youth. In the Art-at-Work program in Atlanta, engaging the youth to participate in the research was a challenge. The program started in the fall of 1996 with 15 participants, by that December only 10 participants were still attending regularly. Complete evaluation data was only collected on 7 of those 10 participants. Although the reported data was lacking in quality, the responses given by the participants and staff suggests that the program was beneficial (Clawson \& Coolbaugh, 2001).

In the Portland site, the Youth Arts Public Art program was geared towards adolescents who committed any delinquent offence except for sex offences. Referrals to the program came from three separate units, but for one of them the program was not considered voluntary. For the two other programs, out of 30 participants who were referred to the program almost $80 \%$ participated. Again, the quality of the data collected was limited, yet there was some indication that the program proved to be beneficial for the participants. In San Antonio, the Urban smARTS program was an after school program designed for 6th graders, in order to prevent them from engaging in delinquent behaviors. More than 400 students were referred to the program from seven school districts. Only 112 of those students participated in the program regularly. Some of the reasons given for dropping out included lack of interest, family obligations and involvement in other programs among others. The quality of the data from the Urban smARTS program was poor because of a lack of good comparison data. The available data did indicate beneficial components to the program.

As the aforementioned study has shown, it is difficult to sustain regular participation of at-risk youth in community art programs and obtain reliable data. To the authors' knowledge, there has been no attempt to conduct an evaluation of a community arts programs for street youth and/or youth in conflict with the law in a voluntary setting. To address the gap in the literature, this study will use data from the Edmonton Arts \& Youth Feasibility Study (EAYFS) which was conducted to assess whether it is possible to engage a group of high-risk youth in a structured and intensive arts activity, and whether the community-based organization implementing this program would be willing and capable of implementing a rigorous research protocol.

The specific objectives of the Edmonton Arts \& Youth Feasibility Study were to:

- Ascertain the feasibility of establishing a structured arts program that can be subjected, at a future date, to an outcome-based evaluation.

- Test the feasibility of conducting a before and after data collection with a very high-risk group.

- Test the acceptability of a structured art curriculum and data collection procedures with the participants. 
The EAYFS arts program is a targeted intervention model, based on positive youth development. That model can be easily subsumed under the research done on risk and protective factors (Catalano, Hawkins, Bergland, Pollard, \& Arthur, 2002). Lawrence (1998) operationalizes positive youth development as an approach to working with youth that assumes that they all engage in a developmental process by which they seek to meet their needs and build competencies. The development is considered positive since it departs from the deficit model by assuming that youths have innate abilities, and that they only need the opportunity to develop these talents. This can best be achieved in environments that underscore strengths and nurture positive child/adult relationships (Lawrence, 1998). Many of the tenets of positive youth development will be reflected in the structure of the proposed program, hypothesized to reduce antisocial behavior and enhance positive behavior. For example, the program will engage youth in productive and life-enriching activities, rather than attempting to correct or treat problems.

\section{Methods}

\section{Design}

Before embarking on a rigorous intervention program with a socially marginal and very high-risk group, it was deemed advisable to first conduct a three-month feasibility study. The study had both a quantitative and a qualitative component. The quantitative component was a pre-post test method. The latter involved collecting baseline data on the youths prior to the 10-week arts program (January 2005) and again after the art program was completed (March 2005). Qualitative interviews were also conducted with youth, site directors, board members of the art organization, art instructors, and research assistants.

\section{Sampling}

iHuman Youth Society, a non-profit organization that functions as a communal art space for Edmonton's high-risk and street youth was selected to participate in the study. Once the site was selected and staff recruited, teleconferences, site visits, and training sessions were conducted with the site director, board members, research assistants, and art instructors to review the research protocol, the development of the art program, the recruitment of youth to the study, the data collection instruments, and reporting guidelines as well as youth management strategies and policies for crisis intervention. Twenty-three high-risk youths were recruited based on referrals from youth workers, social workers, probation officers, and lawyers from shelters, community health organizations, youth offender centres, the youth criminal defense office, and a youth justice committee. Both the youth and their parent or guardian had to sign an informed consent form to participate in the study. In many cases, obtaining consent from a parent or guardian proved difficult as many of the youth were living on their own or on the streets.

\section{The Intervention}

The intervention for the study was a 10-week arts program delivered twice a week for ninetyminute sessions, from January to March 2005. The organization offered a multi-media program that combined graphic, visual, video and digital music workshops. Activities included story development, collage storyboard, animation, photography, field and studio recording, lighting, digital photography, video editing, etc. Art instructors developed and documented the curricula, which targeted artistic and social skills. The aim of the art programs was to provide the youths with the tools they needed to strengthen their cognitive abilities, enhance their social skills and develop interpersonal relationships in addition to developing artistic skills (Wright \& John, et al 2006). It should also be mentioned that iHuman Youth Society offered a multitude of services in addition to the arts programs, such as information and referrals to shelters, drug addiction 
centers, medical centers, legal services, etc. There were also trained social workers on hand to address any crisis that would arise.

\section{Data Collection and Measures}

As previously mentioned, youth completed questionnaires prior to the arts program and after the art program was completed. The study used existing self-administered scales from cycle 4 of the NLSCY to gather demographic information and measure psychosocial outcomes, such as:

- Self-reported delinquency: 14 items on committed offences.

- Self-esteem: a five-item scale measuring the youth's pride in themselves.

- Prosocial behaviour: a ten-item scale measuring the youth's empathic and helpful behavior towards other youth.

- Conduct problems: a seven-item scale measuring bullying, getting into fights, and vandalism.

- Emotional problems: an eight-item scale measuring unhappiness, depression and anxiety

- Smoking, drinking, and drug use.

- Quality of life: eight items measuring the youth's personal satisfaction (or dissatisfaction) with the conditions under which they live.

To augment the quantitative component of the study, the principal investigators wanted to explore stakeholders' perceptions of program activities and processes through qualitative interviews. The aim was to evaluate and document the implementation process, best practices, lessons learned, and sustainability issues. It was also necessary to identify common key elements of crucial importance for successful adaptation of arts-based programming for highrisk youth in other locales. The qualitative interviews were conducted with participating youth, the director and board members of the arts organization, the lead art instructors and the research assistants that served as liaison between the research team and the community site.

\section{Analytical Strategy}

All statistical analyses were done using SPSS statistical package. Attendance rates at the arts program were calculated by dividing the number of sessions attended by the number of sessions offered (20). As previously mentioned, one of the objectives of this study was to ascertain the reliability of obtaining reliable outcome data from such a high-risk group as the present population. One method is to assess the internal consistency of the participants' responses to the indicator-items within a scale that have been previously found to be reliable. Hence, we assessed the internal consistencies of the Youth Questionnaire scales using Cronbach's Alpha (a). If items within a scale purport to measure a common entity, they must be internally consistent. Hence, they should be correlated with one another. An acceptable reliability coefficient is 0.7 (Nunnaly, 1978). Furthermore, the obtained internal consistencies will be contrasted to two other studies, with comparable intervention using similar rating scales.

All interviews were transcribed, reviewed and cleaned in preparation for analysis. We conducted initial coding and categorizing on a sub-sample of interviews from each stakeholder group through line-by-line micro-analysis, employing an established five-stage procedure wherein the data were scanned, edited, refined, and reassembled (McCracken, 1988). Themes were extracted and interpretations made based on emerging data categories, from which we 
developed a coding framework. After developing the initial coding framework, we imported the transcribed interviews into $\mathrm{N} *$ Vivo, a software package commonly used in the analysis of qualitative data, then coded them along the developed framework. Within this process, we employed trained multiple coders to test for inter-rater reliability on the coding and consistency of category development. A sub-sample of interviews coded independently by different coders and themes was developed and reviewed until satisfactory agreement was reached.

\section{Results}

The results are presented as follows:

- Description of sample.

- Attendance and response rates.

- Reliability of selected outcomes from the Youth Questionnaire.

- $\quad$ Findings derived from the qualitative interviews.

Given the small sample size, no inferential statistics are presented. Again, it is important to remember that the purpose of the study is not to evaluate the program's impact but to assess the feasibility of conducting a rigorous outcome-based study in a community setting with a group of high-risk voluntary participants.

\section{Description of Sample}

Twenty-three youth, $39.1 \%$ male (9) and $60.9 \%$ female (14), participated in the study. The youth were between the ages of 14 and 19, and were ethnically diverse, with $51.7 \%$ of youth identifying themselves as Aboriginal, $31 \%$ as White, $7 \%$ as Black, $7 \%$ as Asian, and $3.4 \%$ as Latinos. Approximately two thirds (69.6\%) of the youth did not live with their parents.

Table 1 shows the prevalence of self-reported delinquency for the 12-month period preceding entry into the program. The offences most frequently reported are 'Selling drugs' $(91.3 \%)$, followed by 'damage to property' (78.3\%), 'Stealing from school/store' (69.6\%), 'Fencing stolen property' $(69.6 \%)$, and being in a 'Fight with a weapon' $(69.6 \%)$. 
Table 1

Self-reported Delinquency by Specific Offences

\begin{tabular}{|l|c|c|}
\hline Specific Offence & N & Frequency \\
\hline Stolen money from parents & 11 & 47.8 \\
\hline Stolen from store/school & 16 & 69.6 \\
\hline Damage to property & 18 & 78.3 \\
\hline In fight causing injury & 14 & 60.9 \\
\hline Fencing stolen property & 16 & 69.6 \\
\hline In fight with weapon & 16 & 69.6 \\
\hline Sold drugs & 21 & 91.3 \\
\hline Break and enter & 12 & 52.2 \\
\hline Stolen a vehicle & 11 & 47.8 \\
\hline Set fire to something on purpose & 10 & 43.5 \\
\hline Touched someone who was unwilling & 0 & 0.0 \\
\hline Threatened to get money/possessions & 10 & 43.5 \\
\hline Carried a gun to defend oneself & 7 & 30.4 \\
\hline Forced someone into having sex & 0 & 0.0 \\
\hline
\end{tabular}

Results from the baseline youth questionnaires also indicated that, in the past twelve months, $72.7 \%$ of the youth had used drugs like crack cocaine, heroin, speed, or crystal meth (Methamphetamines). Furthermore, $52.4 \%$ of youth had used hallucinogenic drugs and $54.6 \%$ of the youth used marijuana at least three to five times a week. With respect to suicide attempts and other difficult life events, results from the youth questionnaires indicated that, in the past twelve months, 9 youth (39.1\%) had attempted suicide, with 6 youth $(26.1 \%)$ attempting more than once. It was also found that five of the 14 girls (35.7\%) had been pregnant or had an abortion, 16 youth $(69.6 \%)$ had experienced the death of somebody close to them, and $80 \%$ of youth were physically attacked at least once in the previous year. Other difficult life events identified by youth were fighting addiction, going to prison, and being abandoned by parents.

\section{Attendance and Response Rates}

By dividing the number of sessions attended by the number of sessions offered, the average attendance rate was $48 \%$. We also explored whether the participation was sustained throughout the 10 weeks of programming by looking at the percentage of youth who attended at least once in the last three weeks of programming. Seventeen of the 23 youth $(73.9 \%)$ attended at least once in the last three weeks of programming. With respect to the response rates for the youth questionnaire, $78.3 \%$ of youth completed the questionnaire in Time 1 and $60.9 \%$ in Time 2 . Reasons for not completing the questionnaire included being unable to contact the youth, and incarceration. No youth refused to complete the questionnaire once contacted. 


\section{Reliability of Data from Outcome Scales}

Table 2 shows the reliability coefficients of the self-esteem, prosocial behaviour, conduct problem, and emotional problem scale for the Edmonton Arts \& Youth Feasibility Study (EAYFS), the National Arts \& Youth Demonstration Project (NAYDP), and the Tampa Arts \& Youth Demonstration Project (TAYDP). The NAYDP and the TAYDP were three year studies exploring community-based arts programs as a strategy for enhancing the well-being of children and youth in lower income communities (Wright, et al., 2006). All three studies used similar outcome measures from the NLSCY. As can be seen in Table 2, all studies have Cronbach's Alpha $(\alpha)$ over 0.7 with the exception of the emotional problems scale for the TAYDP. This shows that the scales used for the present study were reliable and that the youth did not complete the questionnaires randomly.

Table 2

Comparison of Internal Consistencies of Scales for Various Studies

\begin{tabular}{|l|c|c|c|}
\hline & EAYFS & NAYDP & TAYDP \\
\hline Self-esteem & .77 & .85 & .87 \\
\hline Prosocial Behaviour & .90 & .83 & .85 \\
\hline Conduct Problems & .75 & .86 & .87 \\
\hline Emotional Problems & .80 & .81 & .66 \\
\hline
\end{tabular}

\section{Qualitative Interviews}

The analysis of the qualitative findings revealed specific issues that are significant for determining the feasibility of the program. Findings are categorized as follows:

- Reasons youth enrolled in the program.

- Benefits obtained from participating in the program.

- Characteristics of the program that helped to facilitate outcomes.

- Program challenges identified by youth and staff.

- Youth's acceptability of the data collection process.

Reasons youth enrolled in the program.

The youth were drawn to the program mainly because it focused on art activities that were appealing to them. Some of the youth mentioned specific activities such as making a video, drawing and painting; whereas others were simply pleased that they would get to participate in art activities, an opportunity they do not normally have.

\section{Benefits obtained from participating in the program.}

The youth identified many personal benefits that resulted from participating in the arts program. A positive impact that the program had on the youth was the specific art skills gained. Some of the favorite activities mentioned were painting, making videos, writing poetry and recording it onto a $\mathrm{CD}$. The youth truly enjoyed the various, diverse and interesting art activities offered. One participant described one of her favorite activities in the following manner: "I liked the random videotaping. We had people running around with cameras, you don't know that they are videotaping you and you are doing something stupid, and you watch it later and you are like 'oh, man'." 
In response to the question "In general what did you learn from the activities in the program?" one youth responded - "how to paint better, different techniques of painting, different things, different canvasses and papers. I never even knew what a canvas was until I came here. I thought it was just a piece of paper."

A number of the youth stated that by participating in the program they were able to stop or decrease their drug use because they shifted their focus, their time and their energy on something else. "I did quit crystal meth because I wanted to do this video. If I didn't quit, I would never show up because I would always be out there doing drugs." Another commonality amongst the youth regarding the personal benefits that they gained was that they were able to learn from one another, learn from each others' mistakes and be able to not replicate the mistakes of others. "I learned more about how they've dealt with different issues in their life, and how they've, you know, we kind of learned from each other, so that we, you know, don't make the same mistakes they've made." The youths described how being part of an art program and interacting with other youth with similar problems has helped them develop social skills. A participant simply stated that she has become "more sociable." When asked to expand on that remark she stated "with being more sociable, I've made so many friends here, different types of people. Normally half the people here wouldn't be the people I would've normally associated with." Some youth stated that the greatest benefit was problem solving. "When you are with people lots of times you kind of get mad at each other. Ways to deal with it I guess. Ways to talk it over instead of fighting."

\section{Characteristics of the program that helped to facilitate outcomes.}

The emerging relationship between the staff and the youth participants was identified as an integral part of the program. All the youth were able to name at least one staff person they would go to if they were in trouble. "I always talk to someone, to the staff about my problems" was how one youth commented on her relationship with the staff. She felt she could trust them. The bonds built among youth were both valuable and educational. One of the most common themes that emerged from the interviews was the ability of the youth to learn from each other. Discussing what she learned from the other youth, one participant stated "instead of learning more about their art, and about how they do their own work, I learned more about how they've dealt with different issues in their life, and how they've, you know, we kind of learned from each other, so that we, you know, don't make the same mistakes they've made. I mean, knowledge in groups is power, it's, why have someone else mistake if you've already learned it right?" In addition to their relationship with the staff and youth, the participants talked about the importance of a non-judgmental environment at the studio.

\section{Program challenges identified by youth and staff.}

The participants' main complaint was the geographic location of the facility. "You got the ... (homeless shelter) right across the street, and they are all doing needles and popping pills. It is just not something I want to see." Another youth's comments reflected the same sentiment, "I really wish this place was not in such a crappy neighborhood. There are some bad sketch cases."

All the stakeholders noted that the facility, in terms of its location and its layout, did not provide an appropriate environment for a structured art program for a group of high-risk youth. It was noted that this had an impact on the artists' ability to deliver the programming. One of the artists felt that "There were so many disciplines working in the one studio. We had art, and the video and the music; it just wasn't enough space for all of us to co-exist and still work as a 
group." The artists felt that the noise levels and the competition for space in the building made it difficult to maintain the participants' attention for any length of time.

Staff members also stated that the preparation time for the program was inopportune. The artists faced the challenge of formulating the appropriate program within the time provided. They felt that the program was invented on the run. One artist remarked "we never had much start up time. So I thought we were a little behind...We sort of invented the program." The research assistants felt the same way with regards to the amount of preparation time that was given before the initiation of the program. For them the main difficulty was the short period allotted for collecting the signed consent forms. Given that transient nature of the participant population and the time of the year, this was a significant challenge. "We needed more lead time to get the permissions from the youth and the time was too short, because it is so hard because they are all over the place and they are under age. Just even finding somebody who can sign a consent form for them is a monumental challenge. We needed more time."

Given the transient nature of these youth, it was difficult to ask them to be at the studio at specific times on a regular basis. The artists raised this concern because they would have liked to progress through the different stages of each module. They were unable to do so because when a participant missed a particular level, the artists would have to review the previous lesson. "What's happening now, you move on to stage two, the stage one kids come in again because you missed them last time so you have to hold the whole class back to go back to lesson one" stated one of the artists. This artist suggested "It would be good to be able to catch them at different times, so you would hold one workshop, hold it several different times and you would finally get them. Then you would hold another workshop, hold it several different times."

\section{Youth's acceptability of the data collection process.}

The youth had complaints regarding the questionnaires that they had to complete at the beginning and at the end of the project. Some commented that they were too long; others stated that it brought up bad memories of a psychiatric facility that they were in and others stated that the questions were "dumb." Suggestions made to address this complaint included creating shorter forms and analyzing and adjusting the questions asked.

\section{Discussion}

To reiterate, the objectives of this study were to shed some light on some basic practical questions with relevance for future program development. The first objective was to assess the potential of street youth, many of them homeless, to be engaged in artistic endeavors. There are certain prevalent assumptions that arts programs targeted to high-risk youth is very challenging in terms of obtaining a sustained commitment (Clawson \& Coolbaugh, 2001; Witt \& Bradberry, 2000). However, the findings from the qualitative interviews were very encouraging and corroborate the assertion that every youth can be brought to a certain level of arts literacy (Pitman, 1998). Just because they are street youth does not necessarily make them unreceptive to such life-enriching endeavors as art. The qualitative findings also support some of the tenets of positive youth development as an approach to working with youth, which assumes that they all engage in a developmental process by which they seek to meet their needs and build competencies.

As a program philosophy, positive youth development departs from the deficit model by assuming that all youths have innate abilities and talents, and that they simply need 
opportunities to develop them (Lawrence, 1998). However, providing opportunity is a necessary component but not a sufficient one. Such opportunities must be provided within a supportive environment, one that underscores strengths and nurture positive child/adult relationships (Catalano et al., 2002; Lawrence, 1998). The qualitative interviews identify the youth relationship with staff that they felt were supportive, as a key component in motivating the youth. Notwithstanding the sporadic attendance, there was committed engagement in the program by the majority of participants. They were interested in the arts programs. Multi-media programming allowed for youth to explore a variety of art forms such as painting, photography, digital editing, etc. They were willing to sign consent forms and complete questionnaires. Cultural mistrust and general mistrust of adults was not a factor, mainly because the organization had credibility with street youth (good word of mouth).

The second objective of the study was to not only assess street youth interest in artistic endeavors but also their motivation for regular and sustained attendance. This is probably the most difficult problem regarding such a high-risk group. Sustained attendance is a problem for not only after-school art programs but all programs. Not all youth who enroll in community programs actively participate and sustain their motivation to stay. Many of them drop out. Community programs could not possibly compensate for all the obstacles to participation faced by those who live in extreme poverty or are faced with a multitude of problems. The participation rates, in the present study, are very encouraging, considering that one of the characteristics of street youths is a high rate of transience.

However, those who were retained participated joyfully and made progress along all behavioral measures. Even though the objective of the study was not to explore the effects of the art program, results indicate that participating youth made appreciable gains throughout the tenweek program. Improved art skills, problem-solving capacity, ability to work with others, cooperation and respect for other youth and adults, prosocial communication were some of the improvements identified in the youth questionnaires and in interviews with youth and staff. The youth also reported a decrease in drug use, depression, and loneliness, and a greater sense of enjoyment about life.

The third objective was to assess the willingness of such a high risk group to complete selfreport questionnaires and show evidence that the questionnaire items were being answered in a reliable manner. As previously mentioned, the internal consistencies of the data were all above .70 and were comparable to two other more rigorous studies.

\section{Conclusion}

With the numbers of street youth growing in Canada, provision of programs to address the needs of this neglected population is desperately needed. We contend that if the necessary services are to be provided to that population it cannot be done at an ad hoc level. The present study has shown that street youth are interested in artistic endeavors; will participate to the best of their idiosyncratic circumstances and provide reliable data. However, sustained participation remains the most salient problems for that population. The question that future research must provide is: What needs to be built into these programs to increase sustained motivation to participate?

The findings from this study, albeit tentative, provide some clues. It is imperative that a safe non-judgmental environment with adults they can trust be the sine qua non of any program for street youth. The program must be staffed by trained social workers / youth workers able to 
manage street youth's emotional and behavioral problems, and refer them to other programs if needed. In order to promote sustained participation, tracking down youth who miss class must be viewed as a fundamental aspect of the program. Attrition rate in community programs range between 30 to 40 percent (Weisman \& Gottfredson, 2001; Billingsley, 2003). If participation rates can be maintained at around 60-70 \%, an outcome-based study would further explore the impact of community arts programs on the psychosocial functioning and quality of life of street youth. Given the youth's capacity to be engaged in community intervention research, this would be a feasible and worthwhile endeavor.

\section{References}

Billingsley, B.S. (2003). Special education teacher retention and attrition: A critical analysis of the literature (COPSSE Document No. RS-2E). Gainesville, FL: University of Florida, Center on Personnel Studies in Special Education.

Catalano, F., Hawkins, J.D., Bergland, M.L., Pollard, J.A., \& Arthur, M.W. (2002). Prevention science and positive youth development: Competitive or cooperative frameworks? Journal of Adolescent Health, 31, 230-39.

Catterall, J. E., Chapleau, R., \& Iwanaga, J. (1999). Involvement in the arts and human development: general involvement in music and theatre arts. Los Angeles: Imagination Project, UCLA School of Education and Information Studies.

Clawson, H. J., \& Coolbaugh, K. (2001). The YouthARTS Development Project. Juvenile Justice Bulletin. Washington: The Office of Juvenile Justice and Delinquency. Retrieved November 29, 2004, from http://www.ncjrs.org/html/ojjdp/2001 5 2/contents.html.

Darby, J.T., \& Caterall, J.S. (1994). The fourth R: The arts and learning. Teachers College Record, 96(2), Columbia University, 299-328.

Eccles, J., \& Templeton-Gootman, J.A. (2002). Community programs to promote youth development. Washington, D.C.: National Academy Press.

Eisner, E.W. (1998). Does experience in the arts boost academic achievement? Art Education, 51(1), 7-15.

Ezell, M. \& Levy, M. (2003). An evaluation of an arts program for incarcerated juvenile offenders. Journal of Correctional Education, 54(3), 108-114.

Jackson, A. (2002). Police-school resource officers' and students' perception of the police and offending. Policing, 25(3), 631-650.

Kempinen, C., \& Kurlychek, M. (2003). An outcome evaluation of Pennsylvania's boot camp: Does rehabilitation programming within a disciplinary setting reduce recidivism? Crime and Delinquency, 49(4), 581-602. 
Kidd, S.A. (2003). Street youth: Coping and interventions. Child and Adolescent Social Work Journal, 20(4), 235-261.

Lawrence, D.H. (1998). Positive youth development promotes pathways of growth. Common Ground 15: 9.

Mahoney, J.L., Larson, R.W., \& Eccles, J.S. (2005). Organized activities as contexts of development: Extracurricular activities, after-school and community programs. Mahwah, New Jersey: Lawrence Erlbaum Associates Inc.

Maslow, A. H. (1954). Motivation and personality. New York: Harper.

McCraken, G. (1988). The Long interview. Newbury Park, CA: Sage Publications.

Offord, D.R., Lipman, E.L., \& Duku, E.K. (1998). Sports, the arts, and community programs: Rates and correlates of participation. Applied Research Branch, Strategic policy, Human Resources Development Canada.

Pitman, W. (1998). Learning the arts in an age of uncertainty. Toronto: Arts Education Council of Ontario.

Posner, J.K., \& Vandell, D.L. (1999). After-school activities and the development of low-income urban children: A longitudinal study. Developmental Psychology, 35(3), 868-879.

Robertson, M.J., \& Toro, P.A. (1999). Homeless youth: Research, intervention, and policy. In. L.B. Fosburg \& D.L. Dennis (Eds.), Practical lessons: the 1998 National Symposium on Homelessness Research (pp.3-1-3-32). Washington DC: U.S. Department of Housing and Urban Development and U.S. Department of Health and Human Services.

Weisman, S. A., \& Gottfredson, D. C. (2001). Attrition from after school programs: Characteristics of students who drop out. Prevention Science, 2(3), 201-205.

Weitz, J.H. (1996). Coming up taller: Arts and humanities programs for children and youth at risk. President's committee on the arts and the humanities with the Americans for the arts. April 1996. http://www.cominguptaller.org/cominguptallerreport.doc

Werner, E., \& Smith, R. (1982). Vulnerable but invincible. New York: McGraw-Hill.

Whitbeck, L.B., Hoyt, D.R. \& Bao, W. (2000). Depressive symptoms and co-occurring depressive symptoms, substance Abuse, and conduct Problems among runaway and homeless Adolescents, Child Development, 71(3), 721-732.

Willms, D.J. (2002). Research findings bearing on Canadian social policy. In D.J. Willms (Ed.), Vulnerable Children (pp. 45-69). Edmonton: The University of Alberta Press.

Witt, P.A., \& Bradberry, E.K. (2000). Evaluation of the totally cool, totally art program. Texas: Austin Parks and Recreation Department. Retrieved November 8, 2004, from http://www.rpts.tamu.edu/Faculty/Witt/conpubs/TCTA00.PDF 
Wright, R., John, L., Offord, D., Duku, E., Rowe, W., \& Ellenbogen, S. (2006). Effect of a structured arts program on the psychosocial functioning of youth from low-income communities: Findings from a Canadian longitudinal study. The Journal of Early Adolescence, 26(2), 1-20.

(C) Copyright of Journal of Youth Development Bridging Research and Practice. Content may not be copied or emailed to multiple sites or posted to a listserv without copyright holder's express written permission. However, users may print, download or email articles for individual use. 